\title{
Paid work is associated with improved health-related quality of life in patients with rheumatoid arthritis
}

\author{
Kjersti Grønning • Erik Rødevand • Aslak Steinsbekk
}

Received: 15 April 2010 /Revised: 14 June 2010 / Accepted: 5 July 2010 /Published online: 20 July 2010

(C) The Author(s) 2010. This article is published with open access at Springerlink.com

\begin{abstract}
Numerous patients with rheumatoid arthritis (RA) end their working career due to consequences of the disease. No publication has reported whether there is an independent association between patients' health-related quality of life (HRQOL) and employment status. The objective of the study was to investigate the association of paid work and HRQOL in patients with RA whilst controlling for demographics and disease severity. This was a cross-sectional study. Three hundred and ten patients were consecutively recruited from two Norwegians hospitals when commencing disease modifying anti-rheumatic drug treatment. Data on demographics, employment status, disease activity (DAS28-3), physical functioning, pain, tiredness, and HRQOL (SF-36) were collected. HRQOL were compared between 123 patients working full- or part-time and 187 patients not working due to disability pension, retirement, being students or "home workers". The regression analyses showed an independent positive association between paid work and the physical $(p=001)$ and the mental component $(p=012)$ of the SF-36 when controlling for demographics and disease severity. Paid work was statistically significantly associated with better HRQOL in patients with RA. The positive association of performing paid work and HRQOL imply that health care providers should thoroughly evaluate the possibilities for the patients to continue with paid work.
\end{abstract}

K. Grønning $(\bowtie) \cdot$ A. Steinsbekk

Department of Public Health and General Practice,

Norwegian University of Science and Technology,

MTFS, Trondheim 7489, Norway

e-mail: Kjersti.Gronning@ntnu.no

K. Grønning • E. Rødevand

Department of Rheumatology,

St. Olavs Hospital, University Hospital in Trondheim,

Trondheim, Norway
Keywords Quality of life · Rheumatoid arthritis · Work

\section{Introduction}

Rheumatoid arthritis (RA) is an inflammatory, painful and progressive disease. Daily perception of stiffness, physical limitations and fatigue are common. Epidemiological studies in Scandinavia report a prevalence of $0.5 \%$ and an annual incidence of 25 per 100,000 of the population [1]. Consequences of the disease are limited abilities to perform paid work and a reduced health-related quality of life (HRQOL) [2-4]. Studies report that more than half of the patients who worked when diagnosed with RA were not working 5 to 12 years later $[5,6]$.

A Norwegian study explored the differences between employed and work-disabled patients with psoriatic arthritis [7]. Low educational level, female gender and reduced physical function predicted work disability. The ability to work in RA depends also on physical and mental health issues [8], along with the type of jobs [9]. However, patients with RA have emphasised the importance of performing paid work for reasons like income, maintaining interpersonal relations and coping with the consequences of the disease [10].

There is sufficient evidence that having RA influences the ability to work $[3,5,6]$. We have identified one study that showed that paid employment was significantly associated with better physical HRQOL, but not mental HRQOL in patients with RA [11]. The conclusions were based on self-reported data and did not include data on objective disease severity measurements collected in clinical practice. Disease severity is linked to perceived HRQOL [4]; it is therefore important to investigate this association when controlling for clinically collected measures of disease severity. 
Therefore, the aim of this study was to investigate the association between HRQOL and paid work whilst controlling for socio-demographics, self-reported and objective measures of disease severity.

\section{Materials and methods}

\section{Study design}

This was a cross-sectional study of patients enrolled in an ongoing longitudinal observational study in five centres in Norway, NOR-DMARD [12]. The data were collected from 2001 to 2003 at two rheumatology departments, The University Hospital in Trondheim and Lillehammer Rheumatism Hospital.

Participants

All patients $(N=310)$ starting a disease modifying antirheumatic drug (DMARD) treatment regime where consecutively invited. The participants were 18-67 years of age with a diagnosis of RA according to the revised American College of Rheumatology criteria [13]. There were no specific exclusion criteria, and a written informed consent was obtained from all patients. The study was approved by the Regional Committee for Medical Research Ethics, health region southeast [12].

\section{Measurements}

Patients' employment status were collected based on the question; "are you currently working, full- or part-time, on retirement, work-disabled, on sick leave, or other?" Our objective was to study the effect of working as being part of a working community, including the social network of a workplace [10], and patients on sick leave were therefore not included in the analyses. Disease severity was calculated according to the disease activity score (DAS 28-3) with 28 tender and swollen joint counts and C-reactive protein $[14,15]$. Furthermore, self-reported visual analogue scales (VAS) for pain and tiredness over the last 4 weeks [16] and the self-administrated modified health assessment questionnaire (MHAQ) for physical functioning [17] were used.

HRQOL was measured by the Norwegian version of the Short Form-36 (SF-36) which performs well in quantifying HRQOL in patients with RA [18, 19]. SF-36 consists of eight subscales ranging from 0 to 100 , where high scores indicate better health. The subscales allow for calculating a global measure of physical (PCS) and mental functioning (MCS) [20]. The lower scores in PCS indicate limitations regarding self-care, physical, social, and role activities, severe bodily pain and frequent tiredness. The lower scores in MCS reflect more psychological distress, social and role disability due to emotional problems [21].

Data analyses

The statistical analyses were performed using the statistical package SPSS for Windows 14.0. [22]. A 0.05 level of significance was chosen for all analyses. Two models for linear multivariate regression analyses were created for each of the SF-36 summary scores with PCS (Table 2) and MCS (Table 3) as dependent variables. For each regression model, independent variables were entered in three steps to

Table 1 Descriptive statistics of all participants

\begin{tabular}{|c|c|}
\hline Variables & All $(N=310)$ \\
\hline Female & $223(72 \%)$ \\
\hline Male & $87(28 \%)$ \\
\hline Age & $50.2(11.6)$ \\
\hline $16-30$ years & $19(6 \%)$ \\
\hline 30-39 years & $42(14 \%)$ \\
\hline $40-49$ years. & $78(25 \%)$ \\
\hline $50-59$ years & $102(33 \%)$ \\
\hline $60-67$ years & $69(22 \%)$ \\
\hline \multicolumn{2}{|l|}{ Education } \\
\hline Elementary school & $111(36 \%)$ \\
\hline Middle level & $110(36 \%)$ \\
\hline University & $86(28 \%)$ \\
\hline \multicolumn{2}{|l|}{ Disease severity } \\
\hline Pain & $48.5(23.6)$ \\
\hline Tiredness & $44.4(29.5)$ \\
\hline MHAQ & $1.7(0.5)$ \\
\hline DAS $28-3$ & $4.6(1.1)$ \\
\hline DAS 28-3 Remission $(<2.60)$ & $9(3 \%)$ \\
\hline DAS 28-3 Low (2.60-3.19) & $27(9 \%)$ \\
\hline DAS 28-3 Moderate (3.20-5.09) & $171(55 \%)$ \\
\hline DAS $28-3$ High $(>5.1)$ & $87(28 \%)$ \\
\hline \multicolumn{2}{|l|}{ SF-36 Domains } \\
\hline Physical functioning (PF) & $49.9(23.4)$ \\
\hline Role—physical (RP) & $24.3(32.5)$ \\
\hline Bodily pain (BP) & $32.4(15.8)$ \\
\hline General health $(\mathrm{GH})$ & $50(18.5)$ \\
\hline Vitality (VT) & $38.6(20.7)$ \\
\hline Social functioning (SF) & $64(26.3)$ \\
\hline Role_emotional(RE) & $53.6(42.5)$ \\
\hline Mental health (MH) & $71.2(18.5)$ \\
\hline \multicolumn{2}{|l|}{ SF-36 summary measures } \\
\hline Role-physical (RP) & $31(8.3)$ \\
\hline Bodily pain (BP) & $48(11.0)$ \\
\hline
\end{tabular}

Mean values and standard deviation (SD) for continuous variables, number and percentage for counts 
Table 2 Multivariate regression analyses of associations to physical HRQOL $(N=310)$
Standardised coefficients $=$ Beta $* p<0.05$

\begin{tabular}{|c|c|c|c|c|c|c|}
\hline & \multicolumn{2}{|c|}{ Block 1} & \multicolumn{2}{|l|}{ Block 2} & \multicolumn{2}{|l|}{ Block 3} \\
\hline & Beta & $p$ value & Beta & $p$ value & Beta & $p$ value \\
\hline \multicolumn{7}{|l|}{ Employment } \\
\hline Working & 0.306 & $<0.001^{*}$ & 0.300 & $<0.001 *$ & 0.178 & $<0.001^{*}$ \\
\hline \multicolumn{7}{|l|}{ Sex } \\
\hline \multicolumn{7}{|l|}{ Male (reference) } \\
\hline Female & & & -0.033 & 0.565 & 0.023 & 0.624 \\
\hline \multicolumn{7}{|l|}{ Age } \\
\hline \multicolumn{7}{|l|}{$<30$ years (reference) } \\
\hline $30-39$ years & & & 0.061 & 0.506 & 0.052 & 0.496 \\
\hline $40-49$ years & & & -0.055 & 0.608 & -0.041 & 0.654 \\
\hline $50-59$ years & & & -0.133 & 0.249 & -0.066 & 0.495 \\
\hline $60-67$ years & & & -0.032 & 0.770 & 0.002 & 0.981 \\
\hline \multicolumn{7}{|l|}{ Education } \\
\hline \multicolumn{7}{|l|}{ Elementary school (reference) } \\
\hline Middle level & & & 0.016 & 0.807 & 0.019 & 0.717 \\
\hline University & & & -0.046 & 0.503 & -0.085 & 0.132 \\
\hline \multicolumn{7}{|l|}{ Disease severity } \\
\hline Tiredness & & & & & -0.150 & $0.006^{*}$ \\
\hline MHAQ & & & & & -0.408 & $<0.001^{*}$ \\
\hline Pain & & & & & -0.100 & 0.101 \\
\hline \multicolumn{7}{|c|}{ DAS $28-3$ remission $(<2.60)$ reference } \\
\hline DAS 28-3 low (2.60-3.19) & & & & & -0.095 & 0.113 \\
\hline DAS $28-3$ moderate $(3.20-5.09)$ & & & & & -0.119 & 0.148 \\
\hline DAS $28-3$ high $(>5.1)$ & & & & & -0.216 & $0.007^{*}$ \\
\hline$R^{2}$ & & 0.09 & & 0.12 & & 0.46 \\
\hline
\end{tabular}

describe the proportion of variance $\left(R^{2}\right)$ in the dependent variable accounted for. We checked for multicollinearity between the independent variables. The intercorrelation ranged from 0.06 to 0.61 .

\section{Results}

A total of 310 patients with RA were included. Descriptive data are shown in Table 1. Patients in paid work were statistically significantly different from those not working $(p<0.001)$ regarding gender (more men), age (younger), higher educated, reporting less pain and tiredness, having lower disease activity (DAS 28-3) better physical functioning (MHAQ), and higher score on all the subscales, PCS and MCS of SF-36 $(p<0.001$; data not shown).

\section{Working and physical HRQOL}

Results from the multivariate regression analyses with the PCS as dependent variable are shown in Table 2. Working was analysed separately in the first step and explained $9 \%$ of the variance in PCS with a positive beta coefficient of $0.306(p<0.001)$, indicating better physical HRQOL for patients who were working. Adding sex, age and education in the second step slightly increased the explained variance to $12 \%$. None of the demographic variables had a statistical significant effect on PCS, but paid work was still significantly associated with better physical HRQOL with a beta coefficient of $0.300 \quad(p<0.001)$. Disease-related variables were added to the analyses in the third step. The final model explained $46 \%$ of the variance in PCS. Paid work remained statistically significant with a beta coefficient of $0.178(p<0.001)$. The disease-related factors MHAQ and DAS28-3 ( $\geq 5.10)$ were associated with worse physical HRQOL.

\section{Working and mental HRQOL}

Table 3 presents the results with MCS as the dependent variable. Working was entered in the first step and was statistical significant with a positive beta coefficient of $0.248(p<0.001)$, indicating better mental HRQOL for patients who were working. Working explained $6 \%$ of the variance in MCS. The explained variance increased to 
Table 3 Multivariate regression analyses of associations to mental HRQOL $(N=310)$
Standardised coefficients $=$ Beta ${ }^{*} p<0.05$

\begin{tabular}{|c|c|c|c|c|c|c|}
\hline & \multicolumn{2}{|c|}{ Block 1} & \multicolumn{2}{|l|}{ Block 2} & \multicolumn{2}{|l|}{ Block 3} \\
\hline & Beta & $p$ value & Beta & $p$ value & Beta & $p$ value \\
\hline \multicolumn{7}{|l|}{ Employment status } \\
\hline Working & 0.248 & $<0.001^{*}$ & 0.222 & $<0.001 *$ & 0.148 & $0.010^{*}$ \\
\hline \multicolumn{7}{|l|}{ Sex } \\
\hline \multicolumn{7}{|l|}{ Male (reference) } \\
\hline Female & & & -0.133 & $0.022 *$ & -0.085 & 0.106 \\
\hline \multicolumn{7}{|l|}{ Age } \\
\hline \multicolumn{7}{|l|}{$<30$ years (reference) } \\
\hline $30-39$ years & & & -0.127 & 0.171 & -0.204 & $0.019 *$ \\
\hline $40-49$ years & & & -0.254 & $0.020 *$ & -0.342 & $0.001 *$ \\
\hline 50-59 years & & & -0.185 & 0.115 & -0.250 & $0.024 *$ \\
\hline $60-67$ years & & & -0.142 & 0.204 & -0.219 & $0.037^{*}$ \\
\hline \multicolumn{7}{|l|}{ Education } \\
\hline \multicolumn{7}{|l|}{ Elementary school (reference) } \\
\hline Middle level & & & 0.004 & 0.951 & 0.017 & 0.775 \\
\hline University & & & 0.055 & 0.431 & 0.063 & 0.327 \\
\hline \multicolumn{7}{|l|}{ Disease-related factors } \\
\hline Tiredness & & & & & -0.281 & $<0.001^{*}$ \\
\hline MHAQ & & & & & -0.077 & 0.230 \\
\hline Pain & & & & & -0.175 & $0.011 *$ \\
\hline \multicolumn{7}{|l|}{ DAS 28-3 remission $(<2.60)$ reference } \\
\hline DAS 28-3 low (2.60-3.19) & & & & & 0.052 & 0.446 \\
\hline DAS $28-3$ moderate $(3.20-5.09)$ & & & & & 0.163 & 0.079 \\
\hline DAS $28-3$ high $(\geq 5.1)$ & & & & & 0.165 & 0.069 \\
\hline$R^{2}$ & & 0.06 & & 0.10 & & 0.31 \\
\hline
\end{tabular}

$10 \%$ in the second step after adding demographic variables to the model. Working remained statistically significantly associated with better mental HRQOL with a beta coefficient of $0.222(p<0.001)$. Being female (beta coefficient of $-0.133, p=0.022$ ) and in the age group 40-49 years (beta coefficient of $-0.254, p=0.020$ ) were associated with worse mental HRQOL. Diseaserelated variables were included in the third step, and the final model explained $31 \%$ of the variance in MCS. Working remained statistically significant and was associated with better mental HRQOL (beta coefficient of $0.148,(p=0.010)$.

\section{Discussion}

There was an independent association between paid work and better physical and mental HRQOL.

\section{Physical HRQOL}

Our results verify a previously reported association between paid work and improved physical HRQOL [11], also when controlling for objective measures of disease activity. It is established that patients with RA have lower physical HRQOL compared to the general population [4] and that the disease influences the patients' working career $[5,6]$. However, our results show that being able to stay in paid work is associated with better physical HRQOL despite disease activity. However, there is some evidence that discontinuing paid work because of RA is related to blue-collar work $[5,8,23]$. We did not have data on specific job characteristics to study the association to job types (like white or blue collar jobs). However, the level of attained education is often linked to whitecollar jobs, and our study did not find a statistically significant association between level of education and physical HRQOL. This may indicate that the type of job has less to do with HRQOL than paid work itself in this study.

As expected, high disease activity by (DAS28-3 $\geq 5.1$ ) and reduced self-reported physical function (MHAQ) were associated with reduced physical HRQOL, which supports already existing knowledge that physical HRQOL is influenced by disease severity in RA [1, 4, 11], as in psoriatic arthritis [7]. 


\section{Mental HRQOL}

Previous studies have shown that staying employed is important to patients and that employment influences patients' mental health positively $[10,24]$. Our results support this. We found a statistically significant independent association between improved mental HRQOL and paid work after controlling for socio-demographic and disease-related factors. The statistically significant association between better mental HRQOL and less pain and tiredness also confirms existing knowledge that pain and fatigue are related to patients' psychological status [2].

Work and HRQOL

The ability to perform paid work has been shown to be important to patients with RA because it gives them a sense of normality and purpose in life, and they feel that they make a difference in society [10, 24]. Our findings strengthen the argument that continuing in paid work has an independent positive influence on people's lives. Despite the significant influence of disease activity, there is still an independent positive association between continuing paid work and improved physical and mental HRQOL. The strong association between disease activity and work ability [3] emphasises the importance of a thorough disease control. In addition, health care providers need to focus on other relevant elements of importance to patients as they want to live "normal lives" and not be regarded differently because of RA [24]. It is shown that adjusting job demands can reduce withdrawal from work life in patients with RA [23]. On the other hand, patients have explained that maintaining paid work also have some "personal costs" due to difficulties in finding the "right balance" between working and resting [10]. Thus, although disease-related factors and medical treatment have a great influence on patients' employment status [3, 23], it is also important to facilitate that patients with RA can continue in paid work by modifying the working conditions [23]. It is still a bit unclear whether work-related costs and savings outweigh the cost of workplace adaptations and occasional sick leave, and we did not have data to investigate this. However, a review article [9] emphasised that anti-TNF therapies helped patients remain in the workforce with less workplace burdens, which consequently reduced workplace costs.

\section{Conclusion}

This study demonstrates that there is an association between performing paid work and better physical and mental HRQOL, also when controlling for sociodemographic data, self-reported and objective measures of disease severity. The clinical implication from this study is to increase the focus on factors that support patients to remain in the workforce.

Acknowledgements This research was supported by Einar Munthes fund, Jan A Pahles legate and The Fund for Special Medical Purposes at St. Olavs Hospital.

Disclosures None.

Open Access This article is distributed under the terms of the Creative Commons Attribution Noncommercial License which permits any noncommercial use, distribution, and reproduction in any medium, provided the original author(s) and source are credited.

\section{References}

1. Uhlig T, Kvien TK, Glennas A, Smedstad LM, Forre O (1998) The incidence and severity of rheumatoid arthritis, results from a county register in Oslo, Norway. J Rheumatol 25:1078-1084

2. Smedstad LM, Moum T, Vaglum P, Kvien TK (1996) The impact of early rheumatoid arthritis on psychological distress. A comparison between 238 patients with RA and 116 matched controls. Scand J Rheumatol 25:377-382

3. Raterman H, Hoving J, Nurmohamed M, Herenius M, Sluiter J, Lems W et al (2010) Work ability: a new outcome measure in rheumatoid arthritis? Scand J Rheumatol 39:127-131, doi: $10.3109 / 03009740903447044$

4. Uhlig T, Loge JH, Kristiansen IS, Kvien TK (2007) Quantification of reduced health-related quality of life in patients with rheumatoid arthritis compared to the general population. J Rheumatol 34:1241-1247

5. Young A, Dixey J, Kulinskaya E, Cox N, Davies P, Devlin J et al (2002) Which patients stop working because of rheumatoid arthritis? Results of fiveyears' follow up in 732 patients from the Early RA Study (ERAS). Ann Rheum Dis 61:335-340

6. Wolfe F, Allaire S, Michaud K (2007) The prevalence and incidence of work disability in rheumatoid arthritis, and the effect of anti-tumor necrosis factor on work disability. J Rheumatol 34:2211-2217

7. Wallenius M, Skomsvoll JF, Koldingsnes W, Rodevand E, Mikkelsen K, Kaufmann C et al (2009) Work disability and health-related quality of life in males and females with psoriatic arthritis. Ann Rheum Dis 68:685-689

8. Odegard S, Finset A, Kvien TK, Mowinckel P, Uhlig T (2005) Work disability in rheumatoid arthritis is predicted by physical and psychological health status: a 7-year study from the Oslo RA register. Scand J Rheumatol 34:441-447

9. Birnbaum H, Shi L, Pike C, Kaufman R, Sun P, Cifaldi M (2009) Workplace impacts of anti-TNF therapies in rheumatoid arthritis: review of the literature. Expert Opin Pharmacother 10:255-269. doi: $10.1517 / 14656560802682163$

10. Simpson C, Franks C, Morrison C, Lempp H (2005) The patient's journey: rheumatoid arthritis. Bmj 331:887-889

11. Chorus AM, Miedema HS, Boonen A, Van Der Linden S (2003) Quality of life and work in patients with rheumatoid arthritis and ankylosing spondylitis of working age. Ann Rheum Dis 62:11781184 
12. Kvien TK, Heiberg LE, Kaufmann C, Mikkelsen K, Nordvag BY et al (2005) A Norwegian DMARD register: prescriptions of DMARDs and biological agents to patients with inflammatory rheumatic diseases. Clin Exp Rheumatol 23(Suppl 39):188-194

13. Arnett FC, Edworthy SM, Bloch DA, McShane DJ, Fries JF, Cooper NS et al (1988) The American Rheumatism Association 1987 revised criteria for the classification of rheumatoid arthritis. Arthritis Rheum 31:315-324

14. van der Heijde DM, van't Hof MA, van Riel PL, Theunisse LA, Lubberts EW, van Leeuwen MA et al (1990) Judging disease activity in clinical practice in rheumatoid arthritis: first step in the development of a disease activity score. Ann Rheum Dis 49:916920

15. Wolfe F (1997) Comparative usefulness of C-reactive protein and erythrocyte sedimentation rate in patients with rheumatoid arthritis. J Rheumatol 24:1477-1485

16. Revill SI, Robinson JO, Rosen M, Hogg MI (1976) The reliability of a linear analogue for evaluating pain. Anaesthesia 31:11911198

17. Pincus T, Summey JA, Soraci SA Jr, Wallston KA, Hummon NP (1983) Assessment of patient satisfaction in activities of daily living using a modified Stanford Health Assessment Questionnaire. Arthritis Rheum 26:1346-1353

18. Kvien TK, Kaasa S, Smedstad LM (1998) Performance of the Norwegian SF-36 Health Survey in patients with rheumatoid arthritis. II. A comparison of the SF-36 with disease-specific measures. J Clin Epidemiol 51:1077-1086

19. Loge JH, Kaasa S, Hjermstad MJ, Kvien TK (1998) Translation and performance of the Norwegian SF-36 Health Survey in patients with rheumatoid arthritis. I. Data quality, scaling assumptions, reliability, and construct validity. J Clin Epidemiol 51:1069-1076

20. Ware JE, Kosinksi M (2001) SF-36 physical and mental health summary scales: a manual for users of version 1. Quality Metric Inc., Lincoln

21. Ware JE Jr, Kosinski M, Bayliss MS, McHorney CA, Rogers WH, Raczek A (1995) Comparison of methods for the scoring and statistical analysis of SF-36 health profile and summary measures: summary of results from the Medical Outcomes Study. Med Care 33(Suppl):264-279

22. George D, Mallery P (2007) SPSS for Windows step by step: a simple guide and reference, 14.0 update. Pearson, Boston

23. Chorus AM, Miedema HS, Wevers CW, van der Linden S (2001) Work factors and behavioural coping in relation to withdrawal from the labour force in patients with rheumatoid arthritis. Ann Rheum Dis 60:1025-1032

24. Ahlmen M, Nordenskiold U, Archenholtz B, Thyberg I, Ronnqvist R, Linden L et al (2005) Rheumatology outcomes: the patient's perspective. A multicentre focus group interview study of Swedish rheumatoid arthritis patients. Rheumatology 44:105-110 